\title{
A NOVEL TECHNIQUE OF RYLE'S TUBE FIXATION (PARTHA'S TECHNIQUE) FOR CONVENIENT INTRAOPERATIVE USE
}

\author{
ARUN THILAK E, PARTHASARATHY S* \\ Department of Anesthesiology, Mahatma Gandhi Medical College and Research Institute, Puducherry, India.
}

Email: painfreepartha@gmail.com

Received: 27 June 2020, Revised and Accepted: 17 July 2020

Keywords: Nasogastric tube, Ryle, Insertion, Fixation, Intraoperative.

(C) 2020 The Authors. Published by Innovare Academic Sciences Pvt Ltd. This is an open access article under the CC BY license (http://creativecommons. org/licenses/by/4. 0/) DOI: http://dx.doi.org/10.22159/ajpcr.2020.v13i10.38884

Dear sir,

Nasogastric tube (Ryle's tube) insertion is one of the most common ward procedures carried out for different indications. During selected surgical procedures, the insertion of such tubes is done in the pre-operative ward. There are lot of reported difficulties during insertion in the intraoperative period [1]. The Ryle's tube is inserted in a classical manner but usually adjusted to enable the surgeon to do the gut surgery. The tube is usually fixed to the nose by a plaster wound round the tube. This technique is usually difficult to unwound if there is a need to reposition. In surgical and medical wards, the necessity for repositioning is not very significant. However, during the intraoperative period, the surgeons always prefer to move the tube here and there to make the operative field better. They also ask for adjustments to position it in a precise location. This, in turn, causes much discomfort to the attending anesthesiologist if the plaster is stuck in a traditional way. Hence, we propose a novel technique of fixation, wherein we get the advantages of avoiding accidental removal but with the ease of frequent positional adjustment. A 65-year-old male came for upper gastrointestinal surgery. The Ryle's tube was inserted in the ward and fixed as given in Fig 1 . To adjust the position after removal of the plaster becomes a herculean task. It is more difficult to adjust the plaster with gloved hands. The plaster was removed before induction and fixed, as described below. The first plaster (P1 in Fig. 2) was vertical and fixed the tube to the nose in a vertical fashion. The portion of the plaster which sticks to the tube should be around $50 \%$ of the plaster length. Usually, there is a small gap between the attachment of the tube and the nose. The next or the second plaster (P2 in Fig. 2) was transverse which fixed the vertical plaster to the nose. The transverse plaster never touched the Ryle's tube (Fig. 2). If we need to adjust the position, the plasters can be easily loosened to adjust and fix again. The portion of the plaster in the gap can be lifted to loosen. There is no need for changing the plasters. Many a time, the surgeons may ask for repeated changes in position during surgery. Hence, this Partha's technique of fixation suits repeated unfastening and regluing. There are reports of lost Ryle's tubes [2] after fixation in the wards. Lorente et al. [3], in his study of intensive care patients, found an incidence of accidental removal of Ryle's tube as $4.48 \%$. A single plaster use may be a cause of malposition. An extensive search of the literature did not reveal fixation techniques with their pros and cons. We have been using this technique for many years with minimal problems. This is a simple case report without any comparative workup with traditional methods.

\section{CONTRIBUTIONS}

- Dr. EA has done the write-up

- Dr. SPS has designed the concept.

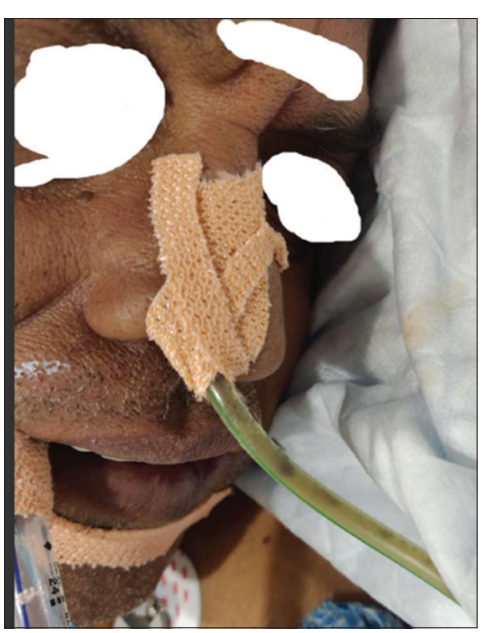

Fig. 1: Wound plaster difficult to unfasten

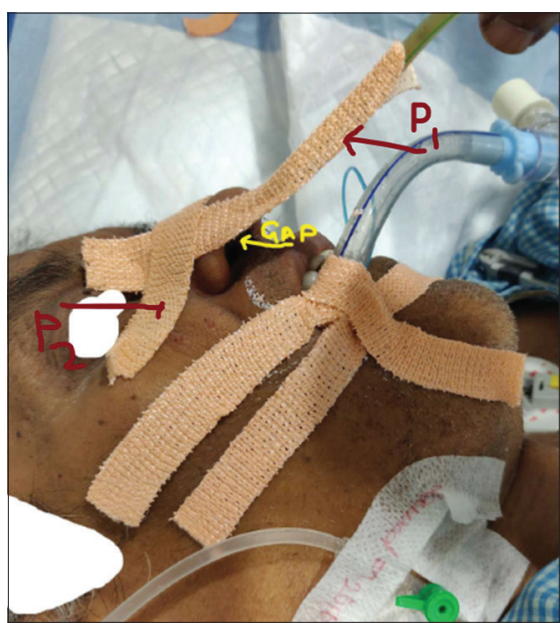

Fig. 2: P1 (vertical) and P2 (transverse)

I/We hereby transfer(s), assign(s), or otherwise convey(s) all copyright ownership, including any and all rights incidental there to, exclusively to the Journal, in the event that such work is published by. The Journal shall own the work, including (1) copyright, (2) the right to grant permission to republish the article in whole or in part, with or without fee, (3) the right to produce preprints or reprints and translate into 
languages other than English for sale or free distribution, and (4) the right to republish the work in a collection of articles in any other mechanical or electronic format.

\section{CONFLICTS OF INTEREST}

Nil.

\section{FUNDING}

Nil.

\section{REFERENCES}

1. Ching YH, Socias SM, Ciesla DJ, Karlnoski RA, Camporesi EM, Mangar D. The difficult intraoperative nasogastric tube intubation: A review of the literature and a novel approach. SAGE Open Med 2014;2:2050312114524390.

2. Sankar V, Shakeel M, Keh S, Ah-See KW. A case of a 'lost' nasogastric tube. J Laryngol Otol 2012;126:1296-8

3. Lorente L, Huidobro MS, Martín MM, Jiménez A, Mora ML. Accidental catheter removal in critically ill patients: A prospective and observational study. Crit Care 2004;8:R229-33. 